\title{
College English Teaching from the Perspective of Ecology
}

\author{
Qifeng Meng \\ Jilin Agricultural University, Changchun 130118, China
}

\begin{abstract}
The use of modern information technology in education is at present more and more widely. This paper, from the ecological point of view, re-examine and do research on College English teaching, after modern information technology entering in College English teaching, studies and explores what kinds of changes happen in College English teaching and what kinds of problems occur, finding roots and sources, and then puts forward the optimization methods of College English education based on ecological theory, expecting to further improve the quality of College English teaching.
\end{abstract}

Keywords: Ecological perspective; College English teaching; modern information technology.

\section{Introduction}

The concept of "ecology" was as early as suggested by the German biologist Ernst Haeckel in 1866. Since the emergence of ecology, it has a close relationship with the production of human life. Especially with the development of society, the ecological research method has penetrated into all the various trades and occupations, become an important part of the human sciences research and provided a new perspective for the development of other fields, and educational ecology is thus derived. Education ecology takes the principle of ecology as the basis, with particular attention to the use of the concept of overall relations and balance [1,2]. It specifically explores the interact relationship and function between various internal structures and the surrounding environment, studies different education phenomenon and the causes, and explores the best method and way to realize the ecological structure of the education.

Ecological teaching is the teaching in the perspective of "system view, the view of the whole, ties concept, concept of harmony, and balanced view". The main characteristics are embodied in the following aspects: first of all, it stresses on respect of life and students' personality and cultivate individual life with physical and mental health and overall development. Secondly, "systematisms and integrity" are the main features of ecological teaching. Thirdly, "open and self - organization" are the key features of ecological teaching. Fourth, "dynamic balance" is the goal of ecological teaching.

\section{Ecological Functions of College English Teaching}

College English is not only an organic whole part, which is also a complete ecological system. It is a special ecological system composed of teachers and students and their teaching environment. It has the dual attributes of nature and society, and it is a whole composed of unique ecological body and ecological environment.

College English teaching, as an ecological system, its internal material flow, energy flow and information flow also reflect the material cycle, energy flow and information transmission between teachers, students, the teaching factors, and internal and external environment factors. It also reflects the language education function of College English teaching in the process of circular input and output, which ensures the orderly operation of the College English teaching system. Therefore, the ecological function of College English teaching is reflected in the material cycle, energy flow and information transmission.

(1) Material circulation in the College English teaching system

Material circulation, as an important function of ecological system, refers to circular motion of the inorganic compounds and elemental through ecological system. Materials in the ecological system of College English teaching is not only the cycle as it is in nature, but also more advanced and complex process, whose basic cycle process can be displayed as Figure 1 shows [3]. 


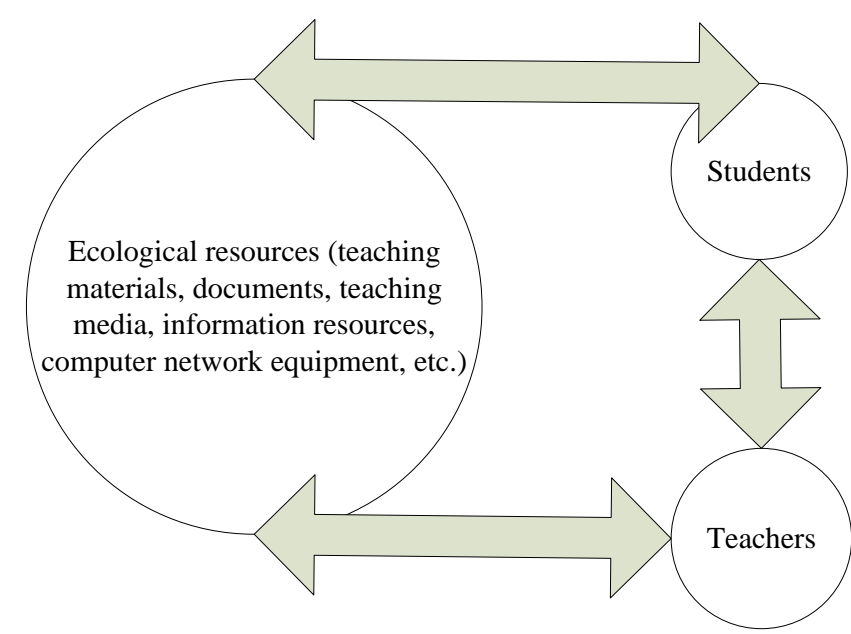

Figure 1 Material cycle of College English Teaching System

(2) Energy flow in the College English teaching system

The energy flow of ecosystem refers to, in the ecological system, the process of a series of energy transferring and transforming from the non-biological environment through the organism, and then to the external environment. Energy in College English teaching system refers to the spiritual or mental state and therefore formed atmosphere and feeling generated in the subjects of the College English teaching ecological because of different culture and background, and also indicates the energy inspired for teaching and learning of College English. The energy cycle is shown in Figure 2.

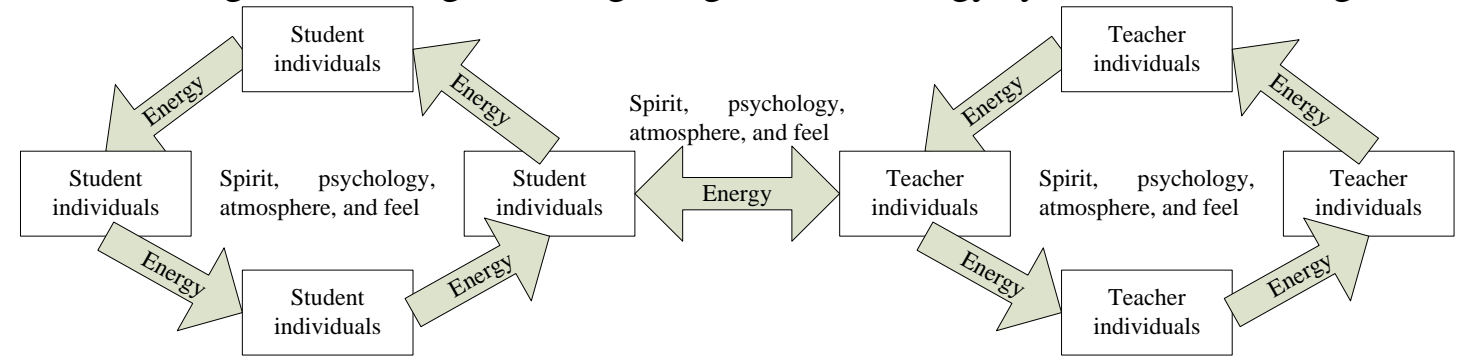

Figure 2 Energy flow chart of College English teaching system

The energy flows inside the population are expressed among the students and the teachers. The energy flow of the population is mainly reflected in the process of the interact functions and influences between teachers and students.

(3) Information transmission in the College English teaching system

In the College English teaching system, except for the material flow and energy flow formed by material cycle and energy flow, there is also information flow, which is realized by the transmission of information of the ecological factors in the system. In a sense, the process of College English teaching in a large extent is the process of information exchange, feedback and transmission, which includes the transmission of various information among different ecological factors in the teaching process, as shown in Figure 3 [4].

College English teaching system contains a variety of information, and the information transmission happens circularly in students and students, teachers and students, teachers and students and environment. The information transmission of College English teaching ecological system is not one-way, but two-way and multidimensional. There is information transmission not only from teachers to students, from teachers to the environment, and from students to the environment, but also information feedback from students to teachers, from the environment to teachers and students, and just the stereo information transmission ensures the smooth of information flow in the ecological system of College English teaching, so as to promote the healthy and stable development.

In short, although the College English teaching system has its particularity and possesses unique subject and environment, it is the same as other systems that they all have a material cycle, energy flow and information transmission functions, and there is stream of material flow, energy flow and information flow in the system. Because of this, in view of ecology, College English teaching system 
is a relative independence, integrated, dynamic and open ecological system, which is suitable for applying the ecological principles and methods to proceed analysis and optimization.

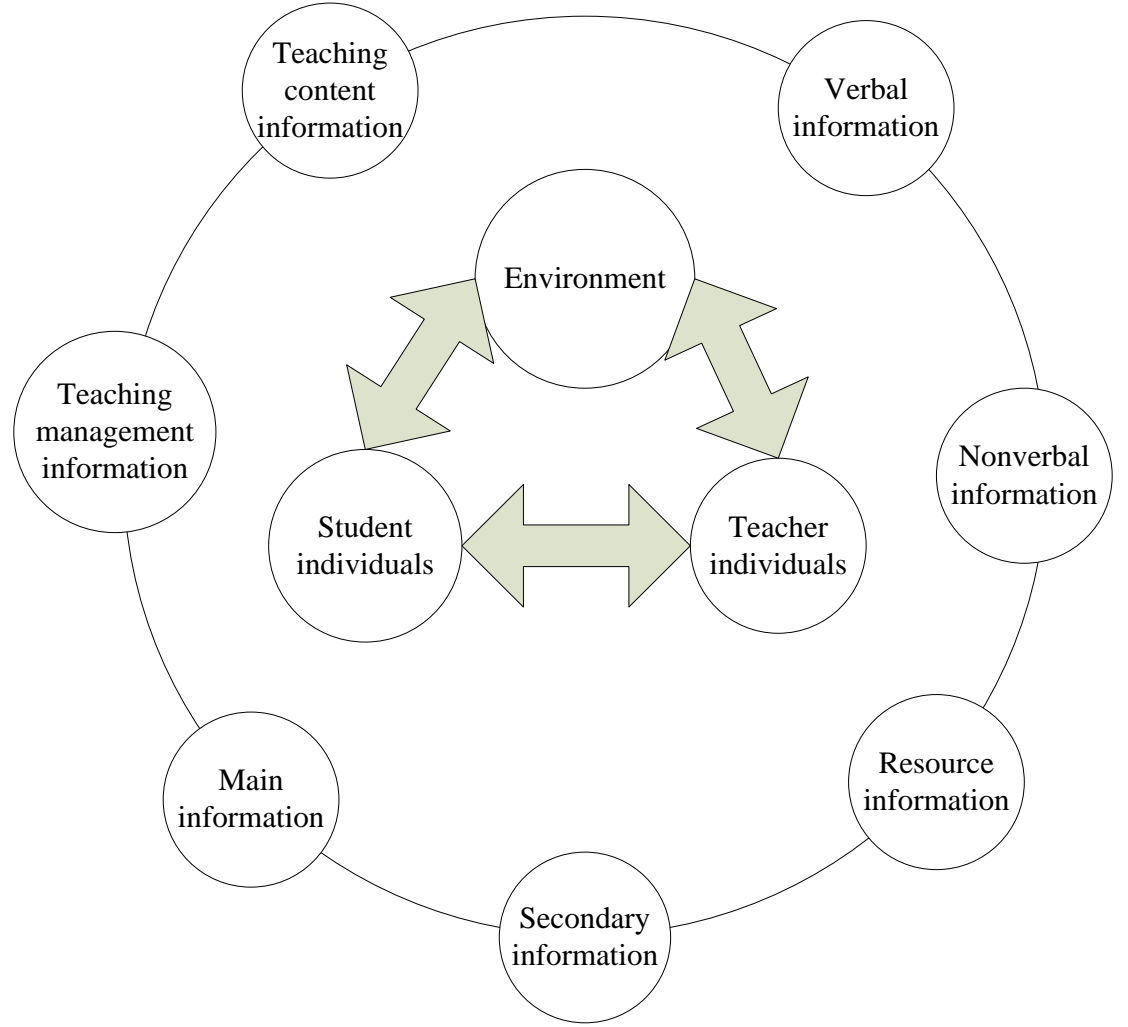

Figure 3 Transmission of College English teaching information

\section{Ecological Interpretation of College English Teaching}

\subsection{Ecological Niche Disorder of College English Teaching and Learning}

According to the viewpoint of ecology, in the ecological system of College English teaching, various ecological factors also have the most ecological niches suitable for their own development, and play its function and role in the corresponding spatial position, so as to ensure the balance and stability of the whole system. Once the ecological factors left the proper ecological position, and appearing the problems of vacancy, dislocation, the overlapping and so on, it will break the original harmonious order and balance of ecological system of College English teaching, thereby reducing the effectiveness of College English teaching [5]. Therefore, in order to guarantee the sustained and stable development of College English teaching, the ecological factors, especially the major ecological factors such as teachers, students and technology must find their corresponding and appropriate niche and play its function and role, and jointly promote the healthy development of the whole system.

In actual teaching, teachers are mainly responsible for the role of knowledge teaching and evaluation, and the students have become the recipient of knowledge. It can be seen that teachers and students have deviated from the ecological niches it should be in College English ecological system under the network environment, and play some functions and roles they should not have. Teachers are still the core of teaching, while they did not play their leading role; students are still passive learners, not in their ecological niches they should be - the dominant position, which is bound to not be able to adapt to the requirements of the development of College English under the computer network environment.

\subsection{Ecological Chain Damage of College English Teaching}

In College English teaching system, various ecological factors like teachers, students, teaching and learning, environment and so on interact and mutually influence each other, and form all sorts of biological chain interlaced with each other. It not only contains the biological chain that takes 
teachers' and students' teaching and learning as the main chain, but also many chains that include classroom and society, acquisition, application and emotional interaction. It is the diversity and life of the biological chain that ensures the ecological development of College English [6]. However, various disorders of College English teaching at current stage reflect the damage of ecological chain in the system, mainly embodying in simplicity of ecological chain, disconnection of ecological chain, and lack of ecological chain these three aspects.

A good teaching atmosphere and healthy emotional environment is the spiritual protection of ecological environment for the students to grow. The relationship between teachers and students, students and students, not only requires the maintenance of knowledge, but also the exchange of thoughts, feelings and wisdom between each other. However, this has not attracted enough attention of College English teaching, which has become a missing link in the teaching ecological chain. In teaching, teachers over-emphasize the teaching of knowledge, while ignore the cultivation of student moral accomplishment, personality and emotion, resulting in the imbalance of material and spiritual pursuit, not conducive to self-control ability and autonomous learning ability training. As a result, students are easily lost in a large number of network resources, and even abandon their studies. Therefore, building a harmonious and caring College English teaching and learning environment is an indispensable link to promote the sustainable development of teachers and students.

\section{Optimization of College English Teaching from the Perspective of Ecology}

\subsection{Optimization Mode}

As mentioned above, there are many imbalances in College English teaching. In order to construct the ecological environment of College English teaching, optimize teaching mode, and construct system with ecological balance, this paper proposes the framework of the College English teaching ecological optimization model. The basic structure and operation mode should be as shown in Figure 4 [7].

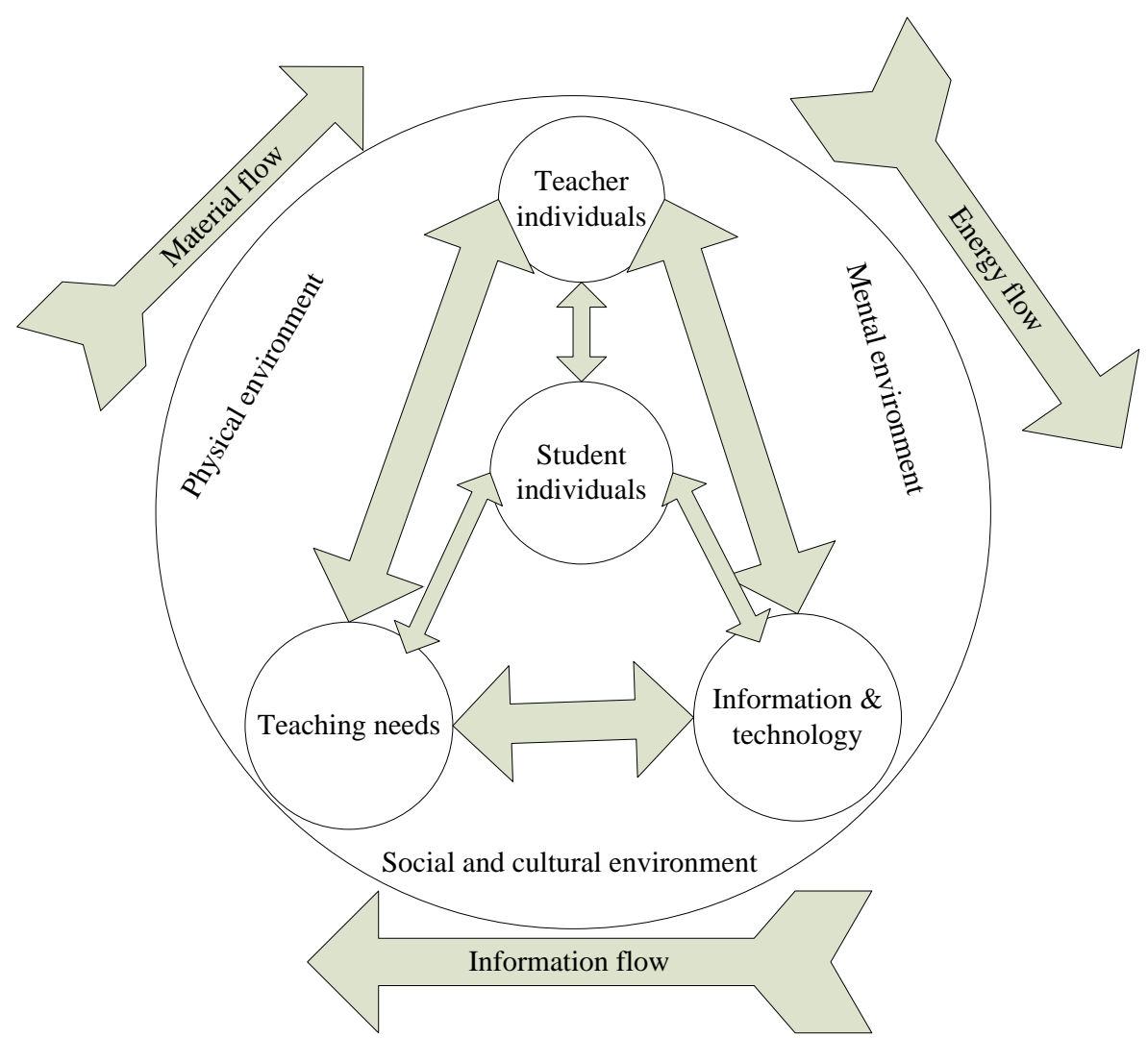

Figure 4 Optimization model of College English teaching system

Optimization model of the College English teaching system constructed in this research not only contains many kinds of ecological factors, but also reflects the complex ecological relationships. It is a dynamically-developed and relatively-balanced ecological system in which ecological factors 
through the interaction and mutual influence to achieve the material flow, energy flow, and information flow.

\subsection{Optimization Principles}

As an ecological system, College English teaching must possess the characteristics of the system, and the components of the system will interact and influence each other, and jointly maintain the stability of the system. Therefore, College English ecological system should firstly have characteristics of ecosystem integrity, emphasizing the combination of each part, which is a unified whole combination of elements within the system. Secondly, ecology believes that any ecological system is not closed, and it is exchange of material, energy and other aspects with the ongoing, so the ecological system is open, and so does the College English ecosystem. Moreover, ecology believes that any system is not immutable or frozen, but constantly developing and changing, and thus College English teaching system should also have the characteristics of dynamic development. Finally, the main characteristics that College English teaching system different from other natural ecological system should be embodied in its life feature, embodying the relationship between people and people, people and the environment. These characteristics are not only what the College English teaching system should have, but also the principle should be obeyed in optimizing the system.

Concretely speaking, the principles of ecological optimization of College English teaching include the principle of sustainable development, the principle of the whole ecosystem, the principle of open ecological system and the principle of dynamic balance with the ecosystem.

\subsection{Optimization Strategies}

(1)Take People as Orientation and the Concept as the First

"People-oriented" refers to take "people" as the starting point and destination, which is the dialectical unity of people's natural, social and spiritual and others aspects. "People-oriented" in teaching stresses the "student-oriented", all things serve for the comprehensive development of students. As a course both have tool feature and humanities, College English, in the teaching process, is supposed to especially set up the thought of "student-oriented". That is to say, it is required to maintain "student-oriented" and "achieve students' sustainable development".

(2)Pay Attention to the Inner Life of the Students

Students are the most essential ecological subject in ecological system of College English teaching, and students stay at the center position in the system. Whether student individual can healthily grow, and whether relations between individuals can get benign development play a significant role in the optimization of the College English teaching system. Student individuals have a difference in the lives. Although their age and profession are similar or identical, each student's background, personality, hobbies, and values are different [8]. Each student is life individual different from other people, and just because of the difference in development level of individual, cognitive ability, and emotional attitude, it makes each student have their own niche. It requires that the teachers should pay more attention to students' different niches, implement personalized teaching strategies according to the characteristics of different students, select and design teaching contents and teaching methods with certain target, and teach students according to their aptitude, so as to achieve the optimization of student individuals' ecological niche.

(3)Attach Importance to the Co-evolution

College English teaching system is an organism composed by the main ecological, teaching factors, information technology and environmental factors and so on, in which the change of any one factor will result in the corresponding change of other factors, and the evolutionary relationships of interaction and mutual influence is called co-evolution. College English teaching, as a complete system, only the internal factors (population) cooperatively develop can it make the whole ecological system reach the balanced and stable state. For optimizing the College English teaching system, must attach importance to each factor, namely the interactions, and promote the co-evolution. 


\section{Conclusion}

Education ecologicalization is an effective way of the development of education. Education ecology emphasizes harmonious development of the relations among the three elements of "people-education-environment". Discussing the concept construction of ecological curriculum, not only embodies the idea of harmonious society, but contains the idea of sustainable development. Using ecological thinking to study education teaching is a mainstream trend. Ecological view used in College English teaching is of positive significance in realizing the ecological sustainable development of English education.

\section{References}

[1] Tang J, Zhang W. A Study on College English Ecological Teaching Strategies in China [J]. Open Journal of Modern Linguistics, 2013, 3(03): 228.

[2] Moon J I. Groping for a new English teaching strategy [J]. Pacific Science Review, 2014, 16(4): 207-211.

[3] Jin Q. Chinese culture to infiltrate into English teaching [J]. Journal of Jiamusi Education Institute, 2013, 5: 147.

[4] Dongchun C. Study on the business-based college English teaching model for language performance improvement [J]. Foreign Language World, 2013, 4: 005.

[5] Qiufang W E N. Application of the output-driven hypothesis in college English teaching; Reflections and suggestions [J]. Foreign Language World, 2013, 6: 005.

[6] Shouren W. On the scientific view of college English teaching reform [J]. Foreign Language World, 2013, 6: 004.

[7] Peng L, Xie F. Rethinking the way out for College English teaching-After China's reform in national college entrance exam in English[J]. Journal of Language Teaching and Research, 2014, 5(6): 1393-1398.

[8] Rocheleau D, Thomas-Slayter B, Wangari E. Feminist political ecology: Global issues and local experience [M]. Routledge, 2013. 